\title{
Analysis of teacher's workspace in a child care center
}

\author{
Vera Helena Moro Bins Elya ${ }^{a}$, Vanessa Dorneles, Flávia Martini Ramos and Mariana Morais Luiz \\ ${ }^{a}$ Federal University of Santa Catarina, SC, Brasil
}

\begin{abstract}
This paper presents one Post-Occupancy Evaluation (POE) done in a child care institution in the city of Florianópolis, in south of Brazil. The objective of this work is to analyze the environment's performance of the child care center considering the well-being of all of its users, with the mainly focus in the teacher's work. For this analyze, was used a multi methods approach, using consecrated evaluations in the area of environmental psychology and ergonomic. The methods used were: Exploratory Visit, Walkthrough, Questionnaires, Observations, Ergonomic Analyze and Poem of Wishes. The methodological procedures used enabled the identification of the main problems that committed the interaction between environment, user and task, which in addition to serve as an argument to the recommendations done to the analyzed Institution, form a repertory that can serve as a base to future projects in institutions with the same character.
\end{abstract}

Keywords: Ergonomic, Children's Environment, Post-Occupancy Evaluation, Environmental Psychology

\section{Introduction}

This paper is the result of the research "PostOccupancy Evaluation of Waldemar da Silva Filho Child Care", in the city of Florianópolis, in south of Brasil, developed in the Universidade Federal de Santa Catarina. The objective of this research is to make a Post-Occupancy Evaluation (POE) in the environment of the child care center focusing in the needs of all of its users and the environment's performance. However, in this paper, will be showed the part of the research that focuses in the teachers' spatial need. In that way, for the realization of this evaluation was looked for a multi methods approach that incorporated ergonomic e psychological aspects. It is believed that these two areas of knowledge complement each other, because the first one consider the system man-task-environment of the point of view of the work's relations and the second one analyses behavior, perception and emotional aspects.

As the environments host different activities, they must conciliate technical and functional aspects, as comfort and safety, with the user's aesthetic expectations (BINS ELY, 2004). As these spaces meet the formal and functional expectations of the users, they allow the possibility of place attachment and even of a greater identity, became one place for users. (TUAN,1980).
For Altman (apud Gifford, 1987), the environmental psychology study justifies itself as the spaces influence people, as well as people change the spaces for assure they well-being.

Related to functional aspects, Moraes and Mont'Alvão (2003) indicate all the aspects to consider in the system man-task-environment analysis: the user in its physical and physiological character, gender and age; the environment, equipments, tools, furniture and installation available for use; * and the kind of activity according to the instruments that are given.

So, it is necessary to understand the physical space of the children day care and its features - colors, textures, visual interference of the structure, disposition of the furniture, functional areas, among others - to examine its influence in the behavior of the teachers, since the space appropriation will influence in the commitment with the teaching activities.

In this paper will be presented the methods used on a Post-Occupancy Evaluation (POE), derived from ergonomic and environment physiology areas and its results.

In the end of the paper, is showed a synthesis of the obtained results, considering the taxonomy of the ergonomic problems proposed by Moraes and

\footnotetext{
* Corresponding authors. E-mail: vera.binsely@gmail.com arq.vanessadorneles@gmail.com flaviamartiniramos@gmail.com marianamoraisluiz@gmail.com
} 
Mont'alvão (2003) and also a Discovery Map, according to Reinghantz et al (2008)

\section{The Child Care Center}

\subsection{The function of Child Care Center}

According to the Art.29 of the Brazilian law $\mathrm{n}^{\circ} 9.394 / 96$, the early childhood education, first step in the basic education, has as a goal the full development of the child until the six years old, on physical, physiological, intellectual and social aspects, complementing the family and the community action.

To accomplish these objectives, these Childs Care are configured by classrooms where there is a collective learning and a same age groups treatment. In that way, children from zero to a year and a half usually stay in the rooms called nursery. From one year and a half until three years, when the children start to walk, they attend the Maternal I, and from then, until the four years and a half, they go to Maternal II. In Brazil, the child cares attend children with six years old, like the kindergartens.

Despite the complex functions of these institutions, their infrastructure uses to present inadequacies and deficiencies, mainly to the workers and teachers, exposing their health. In this way, according to Strenzel (2000), the teacher's performance overtakes the knowledge process mediation, it demands the compensation of the space deficiencies. That factor can expose teachers' health for risks as: development of occupational diseases, discomfort in the exercise of the educational activity, and life quality loss of the professional.

\subsection{Study characterization of the case: The Waldemar Da Silva Filho Child Care}

The Municipal Waldemar Silva Filho Child Care is a public institution of teaching created in 1985 in a preexisting building that since then suffers modifications, adaptations and reforms to attend its needs. Nowadays it assists about 220 students, in the morning and afternoon periods, and it has a functional board composed by about 60 employees, among which 44 are educators with an weekly schedule from 30 hours or 40 hours. The child day care operation period is from Monday to Friday, from 7 a.m. to 7 p.m. This institution attends children from 0 to 6 years.

The Child Care studied is located in one residencial neighborhood, next to the Federal Universtiy of Santa Catarina and to Shopping Iguatemi, so this area have a good acces to public transportation. The figure 1 shows an aerial photo with institution around.

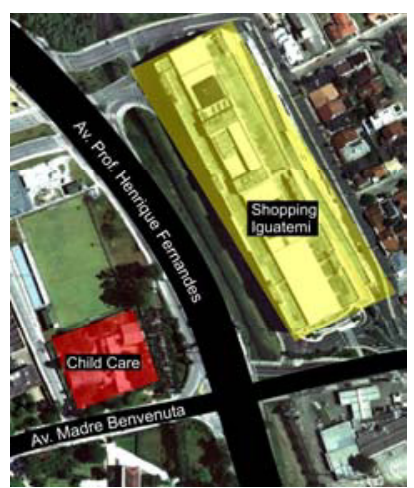

Figure 1 - Schematic plan with institution around.

Adapted from Google maps

\section{Methods}

The methods used for the development of the POE understood five methods, with an interdisciplinary approach: Exploratory Visit (EV), Walkthrough (WK), Questionnaires (QT), Incorporated Observation (IO), Systematic Observation (SO) and Antropometric Evaluetion (AE).

The board 01 bellow shows the aplication' synthesis of each method used, the research's approach and each one sample.

Board 1

Methods: Approach and Sample

\begin{tabular}{|l|l|l|l|l|}
\hline \multirow{2}{*}{ Method } & \multicolumn{2}{|c|}{ Approach } & \multicolumn{2}{c|}{ Sample } \\
\cline { 3 - 5 } & Ergonomic & $\begin{array}{l}\text { Environmental } \\
\text { Psychology }\end{array}$ & Teachers & $\begin{array}{l}\text { Environ- } \\
\text { ment }\end{array}$ \\
\hline EV & & & & \\
\hline WK & & & & \\
\hline QT & & & & \\
\hline SO & & & & \\
\hline IO & & & & \\
\hline AE & & & & \\
\hline
\end{tabular} $\begin{aligned} & \text { Legend: } \\
& \text { Recognition Function } \\
& \text { Deepening Function }\end{aligned}$

The functions of the used methods are divided in two: recognition and deepening.

In the recognition function, the used methods were: The Exploratory Visit and the Incorporated Observation. Both with sample of focused analysis in the environment.

The deepening function relied on a larger number of methods: Walkthrough, Questionnaires, Systematic Observation and Ergonomic Analysis. In this func- 
tion the sample comprehends the space and the teachers' analysis.

In relation with the evaluation approaches, some methods served for both, what confirms the utilization possibility of the two approaches in set.

For better comprehension of the research's application, the used methods will be explained bellow:

\subsection{Exploratory Visit (EV)}

The Exploratory Visit corresponds to the first contact with the institutional environment, when it's accomplished the initial reading of the space with the physical measures and photographic registrations. The method goal is the approach with the environment to be analyzed (REINGHANTZ et Al, 2008).

This method was the first to be applied in the Nursery, and it relied on the presence of the institution representative, its coordinator, that sought to present the physical structure of the nursery, explain employees' routine, and already indicate some of the problems that they come across.

During this first visit some photographic records of the nursery structure were done.

\subsection{Walkthrough (WK)}

The walkthrough configures as a talked route, combining observations and interviews. This method consists in a deepening of the Exploratory Visit, because it also is a visit accompanied by someone from institution. According to Reinghantz et al (2008), the method goal is to describe and give more or less importance to the environment aspects and of its use that have some relevance to the study, so much positively as negatively.

The registration technique of this method is the use of evaluation records that contemplate constructive aspects, of comfort and space configuration, with the blue print support, pictures, audio and drawings recordings.

The Walkthrough was applied in the second visit to the Child Care, where the same institution representative did other guided visit with the researchers, contemplating all the environments. The registration of the identified important aspects was made in a paper with the institution's blue print representation, what already allowed the relation between problems and the environments.

\subsection{Questionnaires (QT)}

The questionnaires, according to Reighantz (2008), consist in a series of questions that should be answered without the presence of the researcher, and can be sent by Internet or personally.

The goal of the accomplished questionnaires was to comprehend the perception of the physical environment by the user and the discomforts and limitations found in the tasks accomplishment.

In this research were performed two kinds of questionnaires. The first had the goal of characterizing the nursery employees and to comprehend their working routine. For such, they had a blueprint of the place in which they should mark, with numbers, the environments in order of frequency along the day. The second questionnaire focused the ergonomics, through the Ergonomic Census, propose by Couto and Cardoso (2007). This, more technical, presented a representation of the human body, in which the interviewees marked the members in which they felt larger discomfort. Its proposal, so, was to identify, through the tired members, the efforts and more harmful activities to the teachers.

The questionnaires were applied with 17 educators.

\subsection{Observations $(O B)$}

The observation method consists in the contemplation and in the environment operation registration without interference at the same by the observer. It supplies information on the performed activities, the necessary relations for their support, conduct regularities, wished uses and about opportunities and behavioral limitations that the environment provides (ZEIZEL, 1995). Its goal, therefore, is the users' interaction comprehension with the space, as well as its configuration. The observation is made through the environment's routine record, writing sentences and sketches in the blueprint.

As the research gathers two distinct approaches, what demands a larger collection of information, it used two kinds of observations: The Incorporated Observations and the Systematic Observations.

\subsubsection{Incorporated observations (I)}

This method is one of the practical unfolding of the experiential approach, practice based on man's experience in the place (Varela et al 2003). He deals with the observation as consciously guided process, and it has the goal of evidencing the relation between man and environment, exhilarating the subjective aspects of this.

This method occurs through the observer sensations registration during his or her experience in the environment, with the goal of deciphering behaviors verified in the activities that the space hosts. For 
such, the observer's posture should be unclosed, with attention and conscious to the influences and emotions provoked by the space, demanding senses and emotions balance.

This methods application was done by one observer, that doesn't know the institution. She does intuitive routes to perceive and register her reactions, effects and sensations. In the end, a table relating the sensations was produced to the present elements in the environment, assisting in the environment influence comprehension in the behavior of its users.

\subsubsection{Systematic observations $(S)$}

This observation is more structured, once it is based in pre-defined points of analysis, derived of the problems identification and discussion. According to Marconi and Lakatos (1990), "in the systematic observation the observer knows what to search and what lacks of importance in determined situation; Should be objective, recognize possible mistakes and eliminate his or her influence on what sees or collect".

In this way, the observers must not interfere in the space; they must observes it with the goal of verifying the environment adaptation to the users. For such, the analysis of the professionals' postures is done during the exercise of their activities, as well as the configuration and disposition of the furniture.

\subsection{Anthropometric evaluation (AE)}

This method was developed along the research with the goal of facilitating the reading of the ergonomic problems raised by the Systematic Observations and Ergonomic Census. It consists in the digital simulations of the teachers activities, considering their statures in relation with the furniture dimensions (BINS ELY et al, 2011).

To perform this analysis, was firstly accomplished a physical data collection of the furniture in the environments. Afterwards the furniture's information and of the teachers stature were drawn in a computational program type CAAD for postural analysis of the activities.

\section{Results}

The results achieved in the evaluation developed will be showed bellow, according to each method used:

\subsection{Exploratory Visit (EV)}

The building configuration can be comprehended according to the educational, administrative, of services and social or of conviviality areas, present in the legend of the Figure 2. The educational area involves 11 classrooms. The administrative area comprehends the coordination, the secretariat and teachers' room. The service areas embrace kitchen, laundry and deposit. And, the social areas or of conviviality have more recreative function, comprehending hall of entrance, the internal circulations, the barbecue set, the video room, the external patios and the hygiene areas, composed by bathrooms and changing table generally shared by two class rooms.

The figure 2 illustrates a confused zoning, for example, there is a crossing flows and displacements problems, due to the distance of some classrooms to the refectory. Any circulations receive groups of 20 students under guardianship of a teacher and one assistant. The children divert of the way and distract the classes that are in the rooms whose doors remain opened.

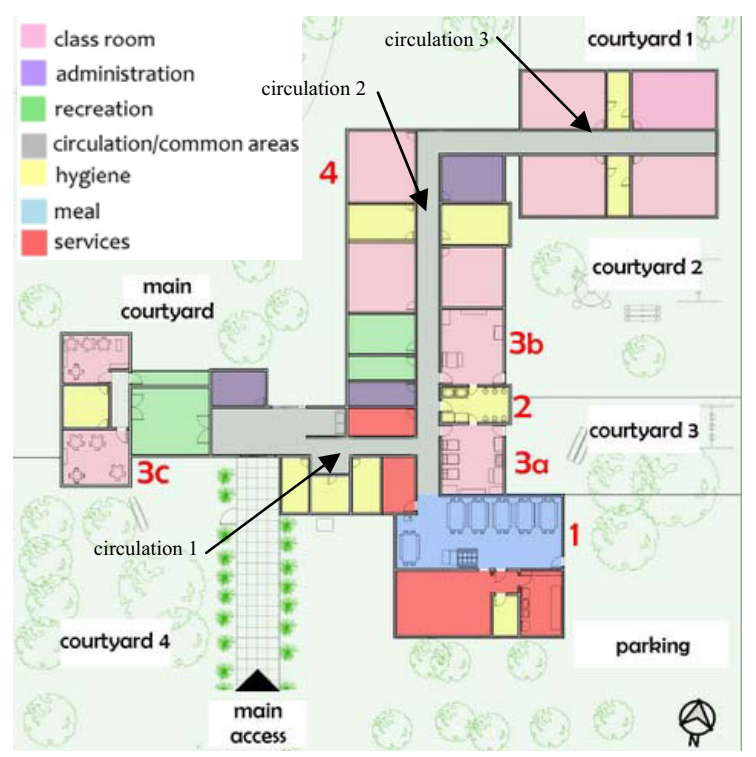

Figure 2 - Schematic Plan. 3a = Nursery; $3 \mathrm{~b}=$ Class room $\mathrm{G} 2 ; 3 \mathrm{c}=$ Living Room; $4=$ Class room G4a.

The hygiene areas contemplate in a comfortable manner all the classes, once they are shared and that its utilization schedule is organized so as to avoid uses conflict. The service areas are the most concentrated, and the deposits located next to the rooms and to the refectory, avoiding big routes to carry equipment and to supply environments. 
The larger conflict verifies in the administrative part, because the offices aren't close and don't have functional identification outside.

\subsubsection{Walkthrough}

This method allowed the sensations analysis, of the uses, of the physical characteristics and of the comfort terms perception and of safety in the institution.

The building has a parking area that is also used as a meeting point for the employees, it has a widespread external area, subdivided in 5 patios partially covered with vegetation and a significant number of medium size trees. For locating itself in a corner, whose frontal and lateral ways present a great flow of vehicles, it has an important noises level, minimized by the present vegetation. A positive highlight is that there are no complaints about acoustics, because the noises produced inside the rooms are not harmful to next rooms, in spite of the great number of children who attend these ambient.

The considerations on the thermal comfort vary according to the rooms, which own very distinct orientations. The constructive system does not contemplate materials or strategies of thermal isolation. Most rooms, however, owns openings of pleasing dimensions placed so as to promote the crusade ventilation, what, allied to the fans' use, alleviates the heat sensation experienced especially in the afternoon. In the Refectory case, that has good air circulation, there is a thermal discomfort of heat caused by lining lowering of PVC in the environment lateral right, next to the kitchen that emanates heat to the whole environment.

Regarding the institution safety, it important to highlight the limits with the external space, which is configured by a barrier of $1,80 \mathrm{~m}$ (low wall + rib). The access is made by a frontal gate controlled with an interphone, however it is common to find it opened. There are no employees responsible by the safety in the institution.

\subsubsection{Questionnaires}

The questionnaires enabled a teachers' characterization and spaces used by them, as well as the discomforts identification through the Ergonomics Census (COUTO and Cardoso, 2007). Most teachers works there for more than one and on integral period, which corresponds to $86 \%$ of the respondents. In this way, these professionals stay along the day in the institution and, therefore, accomplish their meals and keep themselves even in the breaks for rest in this place. Those that just work in a turn, about $50 \%$ have other job. The spaces most use by the teachers are the administrative areas and the refectory. Moreover, their own working rooms, the external areas and the recreative also are very used.

According to the referring answers to the ergonomics census, a discomfort was observed, mostly in the members, in the column, in the shoulders, followed by the neck, of the hip and of the knee. $80 \%$ of the respondents consider activities in the institution as the main cause of these discomforts. The pain is the biggest discomfort sensation. The dormancy and the weariness were also cited.

Beyond these informations, it was possible to discover the main tasks that cause discomfort in the teachers: diapers changes, sit down with the students in classroom and to assist the meals.

\subsubsection{Observations}

The results of this method were separated according to the kind of observation: incorporated and systematic.

\subsubsection{Incorporated observations}

In a routine day of the institution, one researcher walked through in an intuitive manner all the environments, and registered the sensations obtained according to the uses, the occupants, the constructive details and the location. These registrations are systematized in the Board 2

Board 2

Incorporated Observation

\begin{tabular}{|c|c|c|}
\hline $\begin{array}{l}\text { Environ- } \\
\text { ments }\end{array}$ & $\begin{array}{l}\text { Sensa- } \\
\text { tions }\end{array}$ & Justifications \\
\hline Access & Welcoming & $\begin{array}{l}\text { Leafy Vegetation; } \\
\text { Shading; }\end{array}$ \\
\hline Room G4A & Restlessness & Thermal Discomfort; \\
\hline Salon & Disorientation & Amplitude; Furniture absence; \\
\hline Secretariat & Agitation & Small Size; \\
\hline Hall & Disorientation & $\begin{array}{l}\text { Connection with the salon; Signal- } \\
\text { ing lack; }\end{array}$ \\
\hline Aisle 1 & Oppression & Small Width; Little Illumination; \\
\hline Aisle 2 & Fear & Strait; High Right foot; \\
\hline Aisle 3 & Amplitude & Abundance of natural light; \\
\hline Refectory & Restlessness & $\begin{array}{l}\text { Proximity with the street; High } \\
\text { window; Thermal discomfort }\end{array}$ \\
\hline Kitchen & Disposition & $\begin{array}{l}\text { Natural Illumination; Amplitude; } \\
\text { Good furniture organization; }\end{array}$ \\
\hline $\begin{array}{l}\text { Video } \\
\text { Room }\end{array}$ & Comfort & $\begin{array}{l}\text { Comfortable furniture; Darkening } \\
\text { possibility; }\end{array}$ \\
\hline Laundry & Suffocation & Small area; Low right foot; \\
\hline G2B & Comfort & Natural light; Hot colors \\
\hline Patio & Agitation & Aridity; Constant isolation; \\
\hline
\end{tabular}


Between the fourteen analyzed environments, just three produced pleasing sensations and the rest transmitted negative sensations.

With base in the sensations produced by the environments, it can be comprehended educators' behavior in determined situations.

\subsubsection{Systematic observations}

To evaluate the discomforts suffered by the teachers' work, the observations were developed in the environments 1- Refectory; 2- Changing table; 3aNursery, 3b- Class room 2-3 years, 3c- Class room 45 anos. During the observations, the researchers remained in the environments trying to do not interfere in the activities and performed photographic registrations of the teachers' activities.

Among the observed problems stand out: Problems interfacial, accidental, psychosocial, organizational, of displacement, move, space, communicational and informational, as it is better explained in the Board 4.

\subsubsection{Anthropometric evaluation}

Having observed the furniture measurement for adults and children, and having in mind the parallels results of the others methods was possible to analyze users anthropometric evaluations in problematic environments, as is verified in the Board 3.

Board 3

Anthropometric evaluation in the Refectory, Fraldário and Classrooms

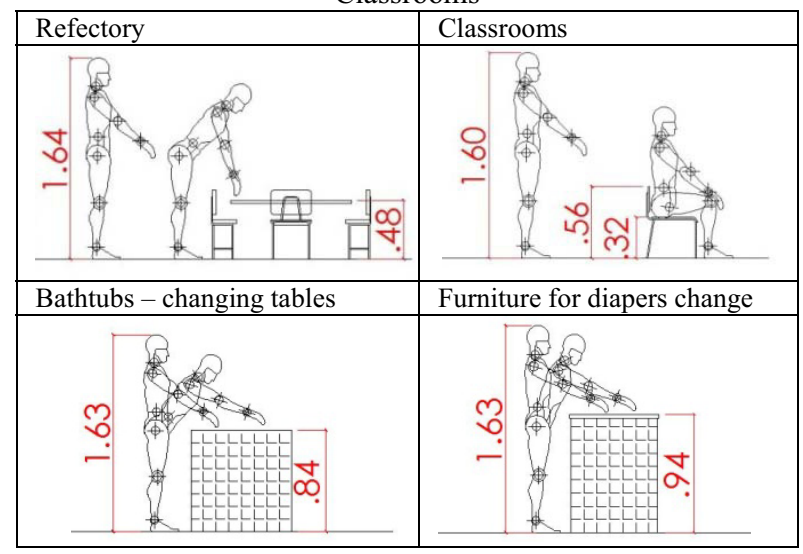

According to the presented evaluations, it realizes that there is a great effort in the tasks accomplishment, once the refectory and classrooms furniture have dimensions adapted to the children. Already in the changing table, it verifies that a bigger height of the piece of furniture for diapers change, allows a more favorable posture to the employee.

\section{Methods discussion}

The methods discussion consists in the aspects synthesis identified during the POA performed. This synthesis is divided into two parts: work aspects (taxonomy problems) and Environment Aspects (discoveries map).

\subsection{Problems taxonomy}

The physical and photographic surveys, opposed to the ergonomics questionnaire and census resulted in a categorization and taxonomy of the ergonomic problems, as proposed classification by Moraes and Mont'Avão (2003). In the Picture 4 are presented the problems as evaluated environment.

Board 4

Ergonomic Problems in the Refectory

\begin{tabular}{|l|l|}
\hline Interfacial Problems & Accidental Problems
\end{tabular}

There are no furniture for the The ceramic floor is smooth and teachers, so they use the child slippery, accident risks may furniture. That causes prob- occur.

lems in their spine, like torsions.

\section{Psychosocial Problems}

There are no options of adequate repose.

Moreover, the dynamics of work associated with the small number of teachers per class requires constant attention and quick movement.

Organizational Problems

The division of the work it is done in an uneven manner, that is, the number of children per professional is not equally divided and therefore the teacher presents overloaded since it is responsible for by a very large number of children.

$$
\text { Displacement Problems }
$$

With the connection between kitchen and refectory in the right hand corner of it, the three observed teachers hadn't to run through great distances, once they occupied the nearest tables. However, in the last tables use, the teachers' displacement is more worrying.

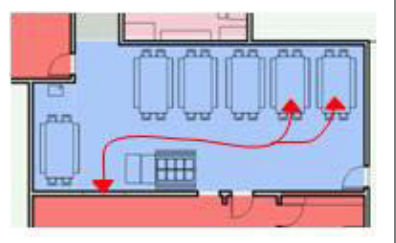


Board 5

Ergonomic Problems in the Changing table Move Problems

The activity demands child's elevation until the top of the piece
furniture where she or he will be changed. One of the teachers
interviewed related being necessary about five daily changes by
child and its working routine belongs to eight daily hours. The
movement repetition, that includes weight rising, carries in col-
umn pains, worsened by the larger children. Moreover, the mate-
rials used during the service are stored in belonging bags of the
children, and there is no space in the piece of furniture to support
them, being usually necessary the teacher repeat up and down
action to catch the material while the child is laid down on the
piece of furniture.

\section{Space Problems}

In the room, the piece of furniture for change stays below a window and next to the door, representing risks. In the room to the side - the little ones' bathroom - where there are more two furniture and two bathtubs, placed so as to form an aisle, the discomfort gives for thermal matters, once there is no ventilation in the location. The furniture, in this case, is placed in a pleasing way and has adequate dimensions, being possible the comfortable work of two teachers so much side by side, how much face to face.

\section{Accidental Problems}

The piece of furniture for diapers change should own certain depth to guarantee the little ones' safety, however, in the bathroom where are the furniture for diaper change and the bathtubs, it is realized the difficulty, by the teachers, of reach some regions.

Board 6

Ergonomic Problems in the Classroom Psychosocial Problems

There are no repose options for the teachers, once the whole furniture inside the class rooms was thought for the children.

The use of this furniture inappropriate on the part of the professionals makes with which is realized the curve of the column and bad angulations of the workers legs.

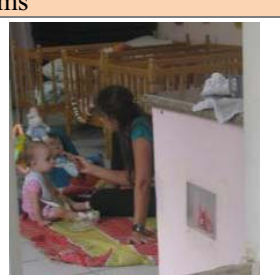

Space Problems

In order to keep the children inside the environment governed by the teachers, they use low fences of $50 \mathrm{~cm}$ of height on the doors. The professionals' circulation, that usually should be fast and without barriers, is committed from the need to pass by the fences' top.

\begin{tabular}{l|l|}
\hline Communicational Problems & Informational Problems \\
\hline $\begin{array}{l}\text { Some rooms are linked to the } \\
\text { patio or receive external noises } \\
\text { to the nursery, what compli- }\end{array}$ & $\begin{array}{l}\text { The Rooms' identification is } \\
\text { made with small leaves of } \\
\text { paper attached to external mur- } \\
\text { cates the communication be- } \\
\text { tween teachers and students } \\
\text { al of the same, what generates } \\
\text { visual pollution and hinders } \\
\text { the readability of information. }\end{array}$ \\
\hline
\end{tabular}

\subsection{Discoveries map}

In order to synthesize the observed results, was elaborated a discoveries matrix, graphic instrument that enables a clearer reading of the whole volume of obtained data from POA, especially those discoveries related to the adaptations, to the technical, functional and behavioral factors, according to the illustrated in the Figure3.

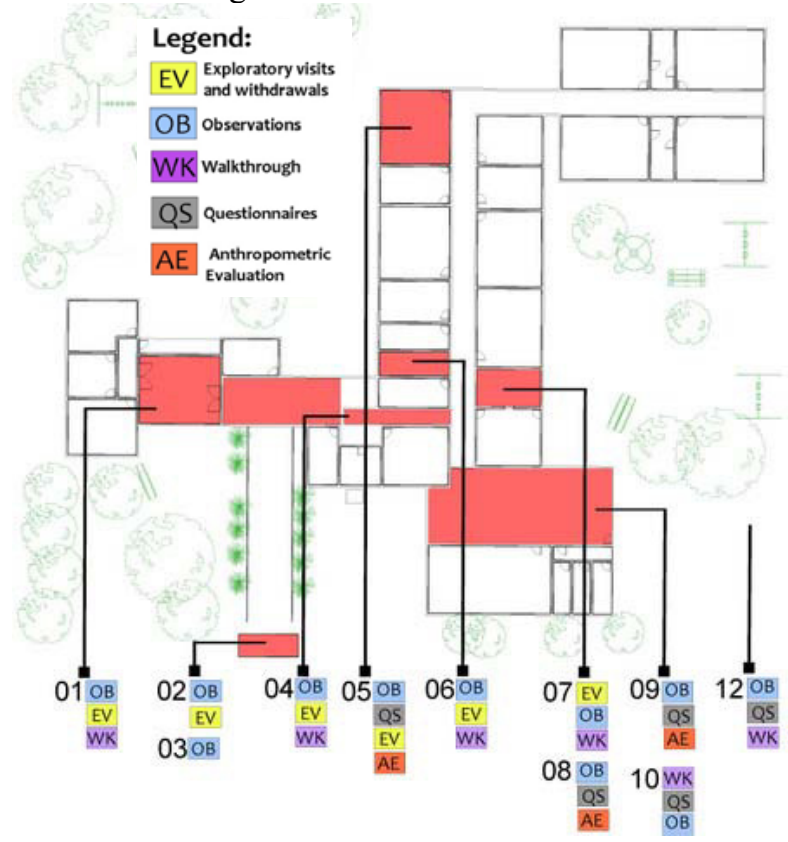

Figure 3- Discoveries Maps

Regarding the used methodologies, it verifies that the Observations (OB) and Walkthrough (WK) have significant importance in the problems revelation. It verifies, yet, need to improvements so much in the common areas, how much in the administrative and of service. In the Board 7, it is possible to observe the description of these problematic. 
Board 7 - Discovery

Discovery

01 Disorientation for lack of legibility in hall of entrance and 01 Salon generated by the signaling lack and adequate furniture.

Problems in the gate closing of the main entrance generate

02 insecurity, once it remains opened frequently incapacitating the entrance control of outsiders in the institution.

03 Main access discovered.

The small width of the circulation prejudice the circulation in

04 emergency situations; Low illumination causes discomfort and oppression sensation.

Problematic class room, since it has an opening to the shakenest patio and an insufficient dimension, what shakes the

05 students and complicates their concentration. The furnitures also were identified as inadequate, having in mind that they are adapted to the children, only.

06 Teachers' room with insufficient dimension: It does not confi-

06 gure a rest space and living room for them.

07 Changing table with high level of thermal discomfort.

${ }_{08}$ Changing table with inadequate disposition of furniture so as

08 to create move, space and displacement problems.

Ergonomic problems found by the teachers to serve the child-

09 ren in the Refectory.

Rest options absence for the teachers.

10 Discomfort generated by the roof lowering.

11 Slippery floor.

12 By the conviviality spaces lack in the institution, the parking

12 is used by the employees for this purpose.

\section{Conclusion}

The factors complexity comprehension involved in the varied relations found in an institution is fundamental for the conception of environments that attend its users' specificities, as well as the activities exercised by them.

The multi methods approach used in this POA enabled a select understanding of the physical, functional, cognitive and social needs of these users and demonstrated its relevance in the elaboration of a complete mapping of the problems and in the environments possible improvements sketch experienced by the users. The joint study of approaches allowed the references and recommendations creation that can serve as base for future projects.

The results' analysis of the several applied methods makes visible that the environment at issue is physically more adequate to the children than to the professionals, what prejudice the development of the educational activity, once unfavorable terms of work affect the health and professional's productivity and, consequently, the children.

This research counts still with the development of technical proposals of improvement of these environments with users' participation and with the elaboration of a project collaborative with the goal of configuring a comfortable and safe environment, that is able to enrich and to improve the institution activities development. This proposal is the last part of the research and is in development phase.

\section{References}

[1] Agostinho, Kátia Adair. O Espaço da Creche: que lugar é este? Dissertação (Mestrado em Educação) - Universidade Federal de Santa Catarina, Florianópolis, 2003.

[2] Bins Ely, Vera Helena Moro; DORNELES, Vanessa Goulart, Casarin, Vanessa. Análise ergonômica da atividade do frentista.IN: $11^{\circ}$ Congresso Internacional de Ergonomia e Usabilidade de Interfaces Humano-Tecnologia: Produto, Informações, Ambiente Construído e Transporte. Manaus, 2011

[3] Bins Ely, Vera Helena. Acessibilidade Espacial - Condição Necessária para o Projeto de Ambientes Inclusivos. IN: MORAES, Anamaria. Ergodosign do Ambiente Construído e Habitado.Rio de Janeiro: iUsEr, 2004.

[4] Couto, H. D. A. \& Cardoso, O. D. S. 2007. Censo de Ergonomia (Online). Available: http://www.ergoltda.com.br/downloads/censo.pdf [Acesso 20 março 2011].

[5] Marconi, Marina de Andrade; Lakatos, Eva Maria Fundamentos de Metodologia Científica. 5ed. São Paulo: Atlas, 2003. 311p.

[6] Moraes, A. D. \& Montal'Alvão, C. 2003. Ergonomia, conceitos e aplicações. Rio de Janeiro, A. de Moraes.

[7] Rheingantz, Paulo Afonso [et al]. Observando a qualidade do lugar: procedimentos para a avaliação pós-ocupação. Rio de Janeiro: Universidade Federal do Rio de Janeiro, Faculdade de Arquitetura e Urbanismo, Pós Graduação e Arquitetura, 2008.

[8] Strenzel, G. R. 2000. A Educação Infantil na Produção dos Programas de Pós-Graduação em Educação no Brasil: Indicações Pedagógicas para a Educação da Criança de 0 a 3 anos. Mestrado em Educação Dissertação Universidade Federal de Santa Catarina.

[9] Zeizel, John. Inquiry by design. Tools for environment - behavior research. Cambridge: Cambridge University Press., 1995.

[10]Tuan, Yi-Fu. Topofilia: um estudo da percepção, atitudes e valores do meio ambiente. Trad. Lívia de Oliveira. São Paulo: DIFEL, 1980 .

\section{Thanks}

We thank the Creche Municipal Waldemar da Silva Filho and its employees, which always welcomed us and enabled its space for the study, making it, once more, a place for experimentation and contributing for the professional qualification. 